\title{
AC 2007-2457: MEASURING THE ENERGY CONTENT OF FOOD: A 'RELEVANT' FIRST LAW EXPERIMENT FOR A THERMODYNAMICS CLASS
}

\section{Brian Sangeorzan, Oakland University}

BRIAN SANGEORZAN (bsangeor@oakland.edu) is an associate professor in the department of Mechanical Engineering at Oakland University. He directs engine research activities at Oakland University and has 23 years experience teaching and conducting research in engine-related fluid and thermal phenomena.

\section{Laila Guessous, Oakland University}

LAILA GUESSOUS (Guessous@oakland.edu) is an assistant professor in the department of Mechanical Engineering at Oakland University. She received her M.S. (1994) and Ph.D. (1999) from the University of Michigan and joined OU in August 2000. Her research and teaching interests lie in the areas of fluid mechanics and heat transfer, with an emphasis on computational methods. She is the program director for the NSF and DoD funded Automotive Research and Industrial Mentorship REU program. 


\title{
Measuring the Energy Content of Food: A 'Relevant' First Law Experiment for a Thermodynamics Class
}

\begin{abstract}
What marginally motivated undergraduate student would not perk up at the thought of working with food or a "bomb", or both, in a thermodynamics laboratory experiment? Sure, our experience has shown that students express some slight disappointment when they find out that the experiment in question does not involve any loud explosions or flashes of light, and that the food amounts are miniscule (on the order of a few grams, sealed in an unappetizing gelatin capsule); but, overall, students greatly enjoy performing the experiment described in this paper, and along the way learn some important lessons about applying the First Law of Thermodynamics and its relevance to our everyday lives.
\end{abstract}

In this paper we describe a thermodynamics experiment that involves measuring the energy content of a food sample, whose contents are unknown to the students. This is achieved by burning the sample in a combustion bomb, measuring the temperature rise of the water in the calorimeter, applying conservation of energy principles to estimate the energy value of the food sample in calories/gram and scurrying down supermarket aisles (or the internet) to collect nutritional information on a number of potential food items. The description will include an outline of the relevant measurements, calculations, engineering principles and their relevance to Accreditation Board for Engineering and Technology (ABET) Program Outcomes.

\section{Introduction}

Engineering Thermodynamics is a basic engineering science that deals with energy and energy transformation, as well as principles of problem-solving that span all engineering disciplines. The importance of energy to our economy and the relevance of energy to current economic, political and social problems cannot be overstated. That said, thermodynamics is often perceived as a difficult subject, and students often have a difficult time seeing relevance for the material during the early stages of their studies. Additionally, in those programs that require a thermodynamics course of all engineering majors, the non-mechanical engineering students often "resist enjoying" the material because they don't immediately see relevance to their curricula or to their everyday lives.

The engineering curriculum at Oakland University consists of a common engineering core that has included engineering thermodynamics since its inception. In the fall of 2004, a Core Curriculum Review Committee was established to study the core and propose a revised common core that would include subject material deemed necessary to a well-rounded engineering education, while considering the additional constraints imposed upon the various programs resulting from accreditation requirements, the incorporation of modern technologies and increasing general education content on our campus. For those of us that wished to see thermodynamics remain a part of the core, 
this meant that we would have to impress upon our students and our faculty colleagues the relevance of thermodynamics.

The curriculum at Oakland University is unusually lab-intensive. That is, the common core courses and many of the electives have a laboratory component as part of the course. Often the laboratory exercises are tied to lecture material so as to reinforce the theoretical concepts as they are taught. While many of the modern thermodynamics textbooks incorporate problems and examples that show the relevance of thermodynamics to our everyday lives, it was felt that it would be even more important to include laboratory exercises that students would find relevant and interesting. A new laboratory experiment, which applies some of the basic principles of thermodynamics in the measurement of food calories, is described in this paper, along with some student results and the connection to ABET Program Outcomes. A survey of students indicates that students find this to be one of the most enjoyable lab experiences in this course.

\section{Course Laboratory Background}

Students are grouped into teams of three to four students. These groups are maintained throughout the semester, and consist of any combination of students from all majors (mechanical, electrical, computer or systems engineers). The students attend a laboratory introduction, typically lasting less than one hour, in which they are introduced to the equipment, the experimental procedures, and any details necessary for the analysis or report. Teams then sign up for a time slot during which they will return to conduct the experiment. This being the second experiment of the semester, the students would have just been exposed to the First Law of Thermodynamics (closed system form) and would have been applying it in homework problems. In an earlier lab, students were taught a method for experimental uncertainty analysis. For this experiment, a knowledge of material property evaluation is required, but has usually not been covered yet at this point of the course. So the lab period is used to demonstrate the application of the First Law to a bomb calorimeter and to preview some basic property relationships. There is a fairly detailed laboratory procedure for nascent experimentalists, and so this lab also emphasizes careful laboratory practice.

\section{Description of the Experiment}

In this experiment, students measure the energy content of a food sample, whose contents are unknown to the students. This is achieved by burning the sample in a combustion bomb, measuring the temperature rise of the water in the calorimeter, applying conservation of energy principles to estimate the energy value of the food sample in calories/gram, and comparing this energy value to values obtained from nutritional information of a number of potential food items. Based on this latter comparison and the results of an uncertainty analysis, students are after-the-fact asked to guess the contents of their food sample. The novelty of this laboratory experiment does not lie in the use of a combustion bomb. Indeed, bomb calorimetry experiments are common, particularly in chemistry and chemical engineering courses ${ }^{1-3}$, and are sometimes used in engineering or 
mechanical engineering laboratory courses ${ }^{4-6}$. For example, students in the first year "Chemistry of Materials" course at Rensselaer

Polytechnic Institute and Virginia Commonwealth University use calorimetry to determine the enthalpy of formation of Sodium Chloride ${ }^{1}$ while students in the "General Chemistry" course for engineering and physical science majors at the University of New Hampshire determine the enthalpy of combustion of oxygenated fuel mixtures using home-made calorimeters ${ }^{2}$. In engineering curricula, combustion bomb calorimeters have been used in courses that focus on introducing experimental techniques to undergraduate engineering students ${ }^{4,6}$ or in undergraduate thermal/fluid laboratory courses ${ }^{5}$. The novelty of this experiment does not lie in the use of a food sample either (although the use of food does not appear to be very common in engineering programs). For example, students in the Biological Sciences "Nature of Human Health and Disease" course at the University of Southern California ${ }^{7}$ determine the number of calories in roasted cashews and popcorn using a homemade calorimeter (which consists of, among other things, a coffee can, a smaller metal can, a glass rod and a piece of cork with wire attached). However, to the knowledge of the authors, students in all of these courses either analyze a known sample or perform the calibration of a calorimeter. In the experiment that we describe in this paper, students do not know a priori what sample they are testing and must hence look up nutritional information of a number of possible food items and identify their unknown food sample based on their calorimetry and uncertainty analysis results. In the sections below we describe some details of the apparatus, procedure and analysis. We also show how this laboratory exercise relates to ABET outcomes. Further details may be found in the Appendix.

Apparatus - The apparatus consists of a Parr Instruments, model 1341 Oxygen Bomb Calorimeter $^{8}$, shown schematically in the Sample Laboratory Handout in the Appendix, plus a supply of bottled oxygen and several extra stainless steel fuel capsules (Parr No. 43AS). The fuel capsules are used to support the food samples within the combustion bomb. They are soiled in each experiment and require cleaning before they are used again. For this reason it's convenient to have several spares so that the teaching assistants can clean them in batches without delaying student groups. In our case, we have replaced the standard thermometer, with a YSI Series 4600 Precision Thermometer ${ }^{9}$. The thermometer uses a precision stainless steel-encased thermistor probe that is much more robust than the glass thermometer. Through a serial port, this thermometer can also be directly connected to a computer for automated data acquisition. The expendable supplies include Ni-Cr fuse wire (Parr No. 45C10), gelatin capsules (Parr No. 3601), weighing paper and whatever food samples are chosen for the testing. For testing of liquid samples (vegetable oils, fuels, or other combustible liquids), a special cellulose tape $\mathrm{e}^{10}$ is used, in place of the gelatin capsules, to seal the sample within the fuel capsule. Each combustion bomb apparatus must be calibrated prior to use in the course using a substance of known calorie content (benzoic acid in our case) to obtain a calibration constant that the students use in their analysis. The calibration procedure used was consistent with the guidelines set by the combustion bomb manufacturer ${ }^{8}$.

Sample Preparation - Food samples are typically selected for a given semester according to a theme. For example, the theme may be breakfast cereals, or snack 
crackers, or vegetable oils. It's a good idea to select foods of approximately the same color so that students cannot easily guess which sample they receive. Liquids require more careful preparation and handling, so this discussion will be limited to dry samples. Prior to the experiment, teaching assistants carefully prepare the food samples according to the following procedure. This sample preparation procedure is in large part based on the manufacturer's manuals ${ }^{8}$. Dry foods are selected and then pulverized using a coffee grinder. For each sample, weighing paper and then a dry gelatin capsule are weighed. The capsule is then filled with the food sample and then reweighed. All weights are recorded to the nearest $0.1 \mathrm{mg}$, and a log of sample number, weights and food sample is prepared as shown in Table 1, below. The food sample, wrapped in its weighing paper, is placed into a sealed and numbered plastic container along with a piece of fuse wire and a stainless fuel capsule. The set of samples are stored in a large plastic storage container along with a dessicant. Since the samples are to be used by the students over a two-week period, the use of a dessicant prevents the contamination of the samples with humidity, which may affect the results of the experiment. A sign-out sheet is attached to the storage container; the students can then record their sample number, and the weights, but will not know which food type they have.

\begin{tabular}{|c|c|c|c|c|l|}
\hline Sample & $\begin{array}{c}\text { Paper } \\
\text { Weight }\end{array}$ & $\begin{array}{c}\text { Capsule } \\
\text { Weight }\end{array}$ & $\begin{array}{c}\text { Paper, Capsule, \& } \\
\text { Sample Weight }\end{array}$ & $\begin{array}{c}\text { Sample } \\
\text { Weight }\end{array}$ & Food Sample \\
\hline \hline 1 & 0.4481 & 0.1162 & 1.4137 & 0.8494 & Corn Meal \\
\hline 2 & 0.4423 & 0.1188 & 1.2306 & 0.6695 & Corn Meal \\
\hline 3 & 0.4315 & 0.1132 & 1.3568 & 0.8121 & Corn Meal \\
\hline 4 & 0.435 & 0.1137 & 1.3475 & 0.7988 & Corn Meal \\
\hline 5 & 0.4521 & 0.115 & 1.4358 & 0.8687 & Basmati Rice \\
\hline 6 & 0.4183 & 0.1167 & 1.39 & 0.855 & Basmati Rice \\
\hline 7 & 0.4442 & 0.1143 & 1.4152 & 0.8567 & Basmati Rice \\
\hline 8 & 0.4304 & 0.1159 & 1.5029 & 0.9566 & Basmati Rice \\
\hline 9 & 0.4323 & 0.1189 & 0.8221 & 0.2709 & Gerber Barley Baby Food \\
\hline 10 & 0.4244 & 0.1141 & 0.8461 & 0.3076 & Gerber Barley Baby Food \\
\hline 21 & 0.439 & 0.1173 & 0.8972 & 0.3409 & Gerber Barley Baby Food \\
\hline 12 & 0.4449 & 0.1158 & 0.9092 & 0.3485 & Gerber Barley Baby Food \\
\hline 13 & 0.4386 & 0.1167 & 1.1698 & 0.6145 & Shredded Wheat \\
\hline 14 & 0.4213 & 0.1152 & 1.065 & 0.5285 & Shredded Wheat \\
\hline 15 & 0.4467 & 0.1156 & 1.1909 & 0.6286 & Shredded Wheat \\
\hline 16 & 0.4421 & 0.1173 & 1.2327 & 0.6733 & Shredded Wheat \\
\hline 17 & 0.429 & 0.1153 & 0.9922 & 0.4479 & Baked Lays Potato Chips \\
\hline 18 & 0.4238 & 0.1127 & 0.9567 & 0.4202 & Baked Lays Potato Chips \\
\hline 19 & 0.4386 & 0.1146 & 1.0061 & 0.4529 & Baked Lays Potato Chips \\
\hline 20 & 0.4582 & 0.1098 & 1.0865 & 0.5185 & Baked Lays Potato Chips \\
\hline
\end{tabular}

Table 1. Sample Preparation Log

Experimental Procedure - Just prior to their scheduled lab time, students pick up a numbered food sample. They conduct the experiment according to detailed instructions given in the laboratory handout (see Appendix). The operating instructions are, in part, extracted from the instrument manual and require careful measurements and lab practice. 
After setting up the experiment, students burn their food sample in the combustion bomb and record the transient temperature rise of the water bath. They also record the length of fuse wire consumed during the combustion process (This information is later used by the students for their First Law analysis). Students wash and dry the combustion bomb and the fuel capsule upon completion of the experiment, and then return the fuel capsule and the sample container to the teaching assistant. (The fuel capsules will be cleaned and reused.) Students record their sample number and retain the temperature-time data for inclusion in their reports. Note that students do not titrate the bomb washings ${ }^{8}$, as might be done in a more thorough analysis or a chemistry course. We've found the chemical corrections for sulfuric and nitric acids to negligible for food samples.

Analysis and Deliverables - In the lab handout, a First Law analysis is outlined for calibrating the combustion bomb using a calorific standard (benzoic acid), in place of the food sample. The resulting calibration constant for each calorimeter is given to the students. Students are then required to develop a very similar model to solve for the food energy, knowing this calibration constant. Their model must include the effect of the gelatin capsule and the fuse wire on the energy balance. Students use their measured temperature history to compute the temperature rise, as outlined in the lab handout. This measured temperature rise is then used to compute the food energy. Note that the students must be careful enough to separate the energy released by the gelatin capsule and the fuse wire.

The students at the outset are not told which food sample they have, but they are given the list of possible candidates. Students must then go to the library, the grocery store and the internet to obtain nutritional information about these food candidates (number of calories in a serving size) and then try to identify which food they were given by comparing this information to their experimental results. Their laboratory reports include: their original sample number, their raw data, the First Law analysis and calculations and their guess as to which food they were given. In our case, we also use the lab to teach data presentation (tables and graphs), report writing skills and uncertainty analysis, and so these elements are also part of their reports. Once the reports are graded, students are informed of the actual contents of their food sample and are hence given an opportunity to evaluate the accuracy of their experimental measurements and analysis.

\section{Student Results}

Some typical results, from the fall 2006 semester, are shown in the figures below. Note that these have not been "selected" to show the "best" possible results. In Figures 1 and 2 , the student measurements are compared to manufacturers' reported calorie data. There are two course sections and the food samples selected were not apparently evenly distributed between the sections. This was coincidental, as the students arbitrarily select samples. Two of the outliers where a result of mistakes made by the students in separating the energy content of the gelatin from that of the food sample.

Another source of the error comes in the preparation of food samples. The food and the gelatin capsules must be dry when weighed, so that the weight does not include any 
absorbed moisture which would confound the energy calculations. Also, manufacturers report average calorie values, which in fact vary due to the source of base food stocks. For example wheat grown in one region of the country during a poor season may have measurable different energy content than wheat grown in a different part of the country during a good growing season. Also, the manufacturers do not always measure the actual energy in their products. Instead, they total the energy values for the components in the food. For example, if a cracker contains wheat flour, salt, sugar and flavorings, the manufacturer might just the total energy content of the components. Some also subtract the fiber content, presuming that the fiber will not be absorbed by the human body. Since the fiber burns, the students will measure a higher energy value than that reported. For the above reasons, it's useful to compare the student results for each food sample, as shown in Figure 2. Student results should be clustered, for a given sample, even if that cluster differs from the manufacturer's stated energy. One can see that in Figure 2, except for the one outlier in the basmati rice and one in the Gerber ${ }^{\mathrm{TM}}$ Baby Cereal, the student data looks well-clustered. (These were the two outliers mentioned earlier.)

\section{Benefits}

By conducting this experiment, students come to appreciate the relevance of the principle of conservation of energy to every day life. Up until this point, most have never thought about how nutritional content information is obtained and are excited to see that what they learn in a thermodynamics class doesn't only have bearing on engineering applications, but also on everyday life. Anecdotally, one of the discoveries students make is that "food" calories are actually kilocalories. That really puts perspective on what we eat!

The careful procedure and attention to details that are required in this experiment are also important to the education of thorough and thoughtful engineers. Along with this comes an important lesson in the analysis and interpretation of data. By requiring students to perform an uncertainty analysis on their measurements and data, they realize that it is often not sufficient to only look at the energy content result to identify the food sample. Indeed, some of the food samples have very similar calorific content and the energy value uncertainty is at times larger than the difference between the calorific content of two different food items. In such cases, students can only narrow down the list to a few candidates but cannot make a more "certain" identification. Of course, by picking food items that have significantly different energy values, this issue becomes minor. 


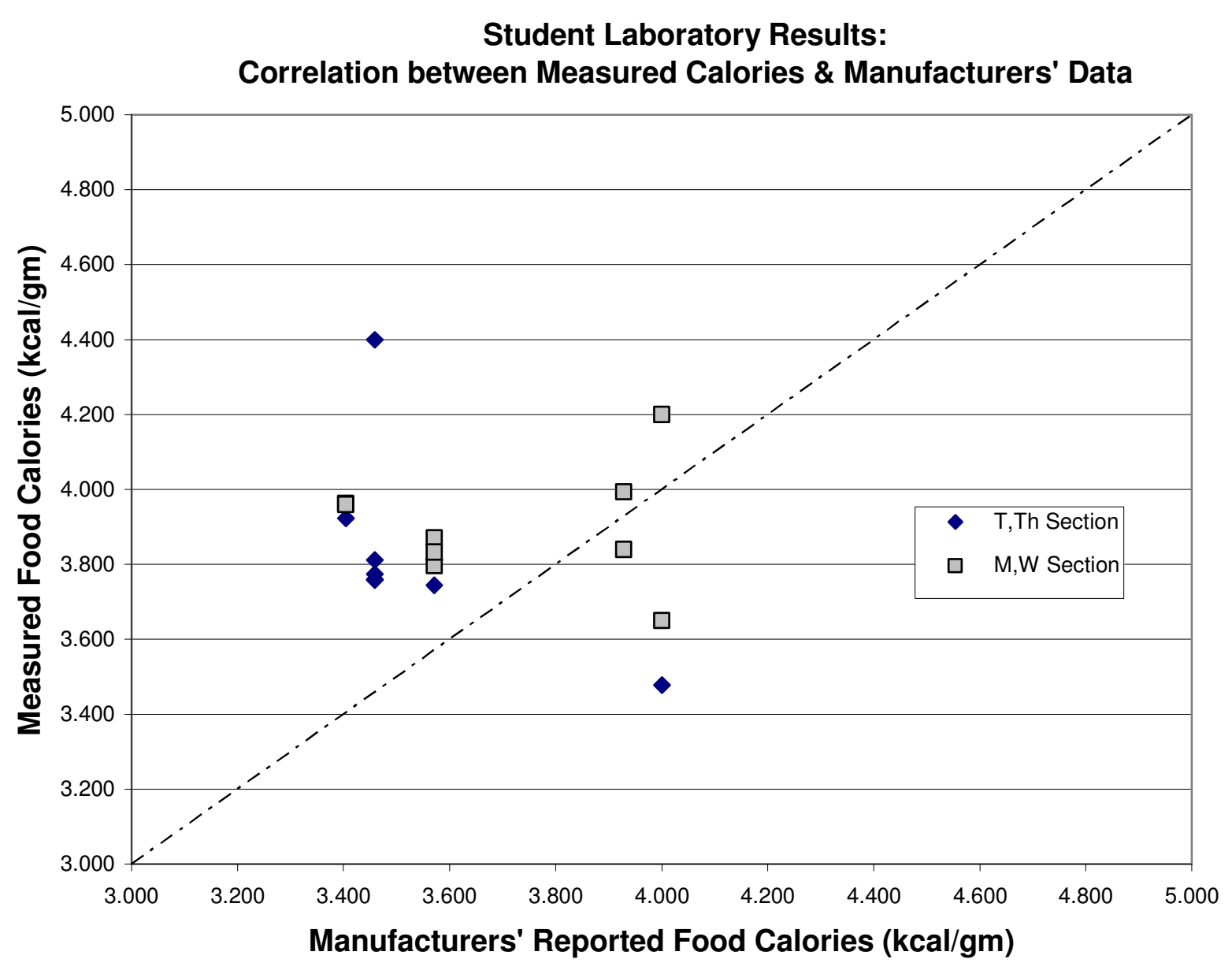

Figure 1. Sample Student Results Compared to Manufacturers' Data 


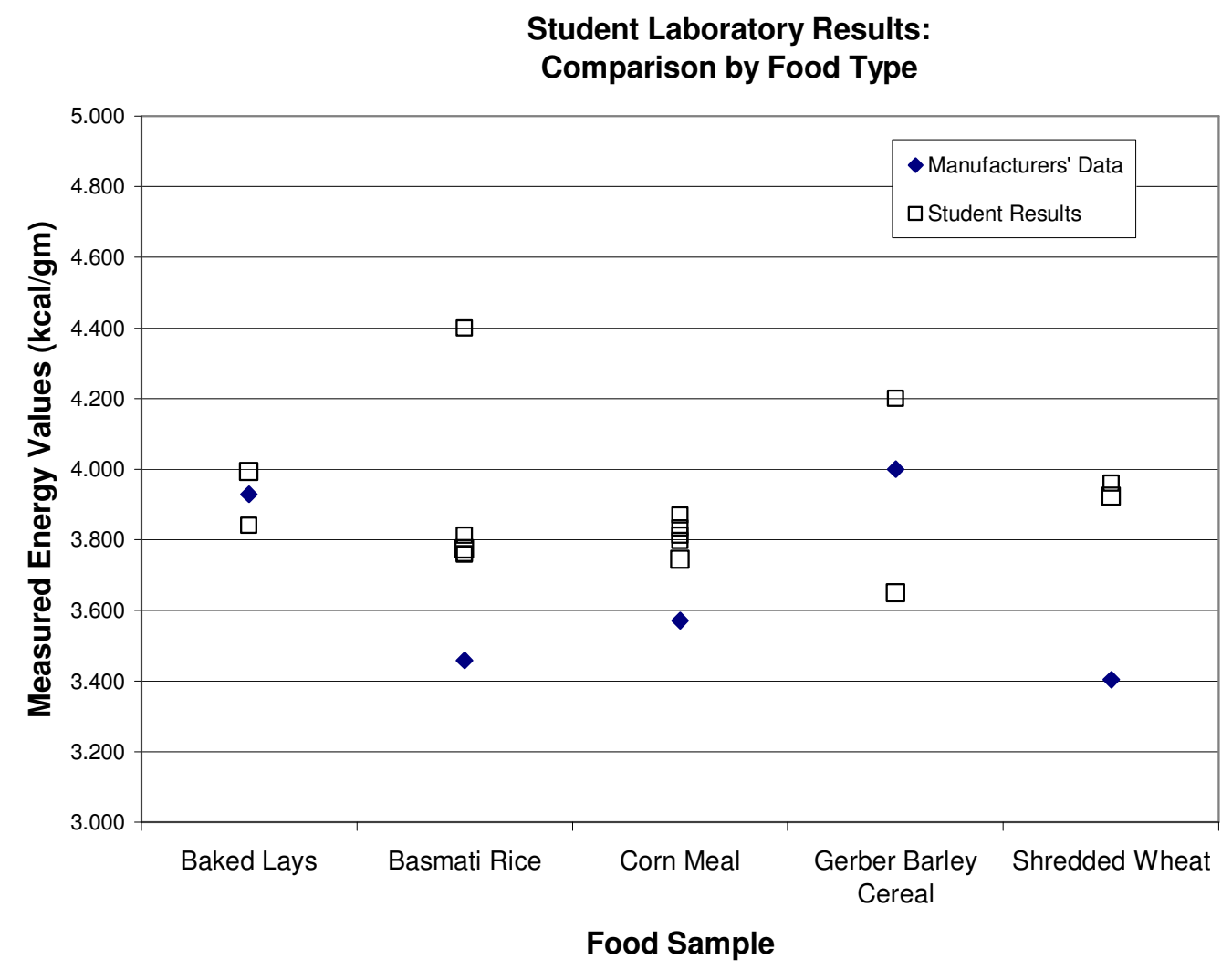

Figure 2. Sample Student Results by Food Sample

Another benefit that we see relates to the achievement of ABET outcomes. Currently, engineering programs must demonstrate that their students attain ${ }^{11}$ :

(a) an ability to apply knowledge of mathematics, science, and engineering

(b) an ability to design and conduct experiments, as well as to analyze and interpret data

(c) an ability to design a system, component, or process to meet desired needs within realistic constraints such as economic, environmental, social, political, ethical, health and safety, manufacturability, and sustainability

(d) an ability to function on multi-disciplinary teams

(e) an ability to identify, formulate, and solve engineering problems

(f) an understanding of professional and ethical responsibility

(g) an ability to communicate effectively

(h) the broad education necessary to understand the impact of engineering solutions in a global, economic, environmental, and societal context

(i) a recognition of the need for, and an ability to engage in life-long learning

(j) a knowledge of contemporary issues

(k) an ability to use the techniques, skills, and modern engineering tools necessary for engineering practice. 
This laboratory exercise addresses a number of ABET outcomes, as summarized in the following table.

\begin{tabular}{|c|l|}
\hline $\begin{array}{c}\text { ABET Criterion 3. } \\
\text { Outcome }\end{array}$ & \multicolumn{1}{c|}{ Means of Addressing or Achievement } \\
\hline $\mathbf{a}$ & through the application of the first law of thermodynamics \\
\hline $\mathbf{b}$ & $\begin{array}{l}\text { through careful experimentation, analysis and interpretation of } \\
\text { the results, including and uncertainty analysis }\end{array}$ \\
\hline $\mathbf{d}$ & if the experiment is conducted in teams \\
\hline $\mathbf{e}$ & $\begin{array}{l}\text { through formulation of an energy balance model and subsequent } \\
\text { solution }\end{array}$ \\
\hline $\mathbf{i}$ & $\begin{array}{l}\text { through a written laboratory report and/or oral presentation } \\
\text { by requiring students to seek outside sources of information } \\
\text { (nutritional value) and discover how that information or data is } \\
\text { determined }\end{array}$ \\
\hline $\mathbf{k}$ & $\begin{array}{l}\text { through the use of engineering skills and tools to solve the } \\
\text { problem of the "unknown food sample." }\end{array}$ \\
\hline
\end{tabular}

Lastly, the students seem to enjoy this experiment. We regularly survey students about the course and the lab experience. We ask them which labs they enjoy the most and which they enjoy the least. This food calories lab is almost always rated first or second in these surveys. This was the motivating force for developing this experiment in the first place. 


\section{Acknowledgement}

The authors wish to thank Dr. Peggy Lin who, as a graduate student, diligently conducted many of the preliminary tests of many types of food samples, as well as the calorimeter calibration experiments. She also took the time to train several teaching assistants in the preparation of food samples.

\section{References}

1. Mark A. Palmer, Gary E. Wnek, Joseph Topich, John B. Hudson, and James A. Moore, "A OneSemester Engineering Chemistry Course," Proceedings of the 2002 American Society for Engineering Education Annual Conference \& Exposition

2. Carmela Amato-Wierda, Christopher F. Bauer, Eleanor Abrams, David Bourgeois, Anneliese Mueller, and Emma Torbert, "A Laboratory-Driven General Chemistry Course for Engineering and Physical Science Majors," Proceedings of the 1999 American Society for Engineering Education Annual Conference \& Exposition

3. http://www.chem.queensu.ca/PROGRAMS/UG/Firstyearlabs/apsc100/calorimetry.htm. Accessed, March 3, 2007

4. Marty Matlock, Scott Osborn, Wayne LePori, and Cady Engler, "Development and Implementation of a Common Investigative Methods Course for Undergraduate Engineering Students," Proceedings of the 2001 American Society for Engineering Education Annual Conference \& Exposition

5. H. W. Shawn Kim, "Improvement of an Undergraduate Thermal Fluid Laboratory Through Innovative Laboratory Design Projects," Proceedings of the 2004 American Society for Engineering Education Annual Conference \& Exposition, Paper \# 2004-1382

6. Risa J. Robinson and John Wellin, "Introducing Data Acquisition and Experimental Techniques to Mechanical Engineering Students in the Freshmen Year," Proceedings of the 2002 American Society for Engineering Education Annual Conference \& Exposition,Paper \# 2002-2370

7. "Burning Calories: The Energy in Food", accessed on March 3, 2007 at http://bioweb.usc.edu/courses/2004-fall/documents/bisc150-lab_burningcal.pdf

8. OPERATING INSTRUCTIONS: For the 1341 Oxygen Bomb Calorimeter, publication no. 204M, Parr Instrument Company, Moline IL, http://www.parrinst.com.

9. YSI 4600 Series Precision Thermometer, http://www.ysitemperature.com/ind-instruments.html

10. Standard Test Method for Heat of Combustion of Liquid Hydrocarbon Fuels by BombCalorimeter, ASTM Standard D240-02, ASTM International, West Conshohocken, PA, http://www.astm.org.

11. Criterion 3. Program Outcomes and Assessment, in CRITERIA FOR ACCREDITING ENGINEERING PROGRAMS, October 28, 2006, ABET Inc., Baltimore, MD, http://abet.org/index.shtml. 


\section{Appendix - Sample Laboratory Assignment}

Fall 2006

\section{$<$ Course Name $>$}

$<$ Course No. $>$

Laboratory Assignment \#2
$<$ Professors Names $>$

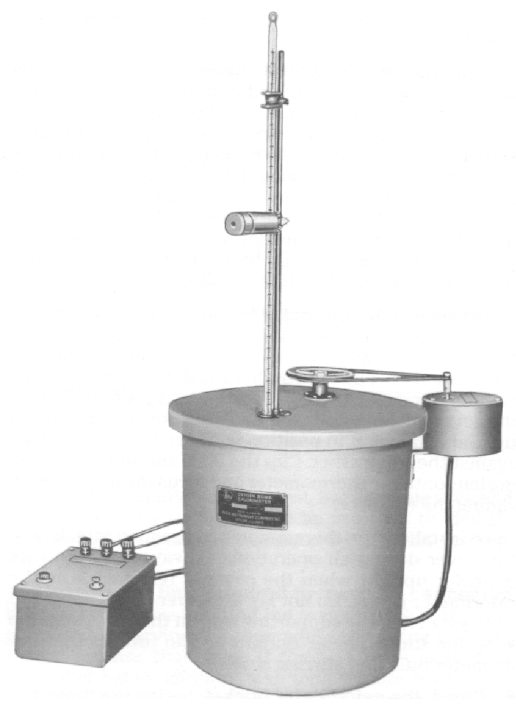

\section{Measuring the Energy Content of Food}

The purpose of this laboratory exercise is to apply the First Law of Thermodynamics to determine the energy content (i.e. food calories) of some simple foods.

1. Carefully read the operating instructions for the Parr Instruments ${ }^{\circledR}$ model 1341 Oxygen Bomb Calorimeter. Ensure that every group member has thoroughly read the instructions. Discuss the details of the experiment so that you are properly prepared before attempting to conduct the experiment, as you will be given only one food sample. Prepare a data sheet for recording the water-bath temperature rise, as discussed in the operating instructions.

2. Sign-out a food sample in room 145 DHE. You should do this just prior to conducting the experiment. Do not open your sample capsule. The capsule and contents have been weighed to the closest $0.1 \mathrm{mg}$. Moisture will damage the gelatin capsule.

3. Prepare the oxygen bomb, using your food sample, and burn the sample within the bomb calorimeter. Record the water-bath temperature as detailed in the handout. If you have any questions about operating the calorimeter, please ask before you attempt the experiment.

4. Return your sample cup to room 145 DHE immediately after the experiment.

5. Plot the water-bath temperature as a function of time, and determine the actual temperature rise.

6. Develop a First Law model of the system that is composed of the water-bath, bomb, fuse wire and food sample. Use your model and the measured temperature rise, to estimate the energy value, $e_{f s}$, of your food sample ${ }^{1}$ in cal/g and 'food calories"/g. Note that one 'food calorie' is equal to one kilocalorie.

7. Perform an uncertainty analysis on your calculation of $e_{f s}$, and specify the magnitude of the uncertainty for your experiment.

8. Your sample consists of one of the following: Shredded wheat ${ }^{\mathrm{TM}}$, Original Baked Lay's ${ }^{\mathrm{TM}}$ potato chips, Gerber barley baby cereal, basmati rice or yellow cornmeal. Research the calorie information for these foods and tabulate in your report (include \# food calories, serving size (g) and energy value). Which sample would you guess that you measured? Justify your answer.

\footnotetext{
${ }^{1}$ The derivation in the combustion bomb instruction sheet does not consider a gelatin capsule. You must modify the derivation to account for the capsule by decomposing the total "energy release" from the test sample into 2 terms: one accounting for the food sample itself and the other for the gelatin capsule. The heat of combustion of the gelatin capsule is $\mathrm{E}_{\text {equiv/gc }}$ and is listed in the preliminary calculations section of the handout.
} 


\section{OPERATING INSTRUCTIONS For the Parr 1341 Oxygen Bomb Calorimeter}

These instructions cover the steps to be taken in setting up and operating a Parr 1341 Plain Oxygen Bomb Calorimeter. They are extracted from the manufacturer's complete manuals, which are available upon request. The user should study these instructions carefully before starting to use the calorimeter so that he/she will fully understand the capabilities of the equipment, and so that he/she will be well aware of the safety precautions to be observed in its operation.

\section{OPERATING THE CALORIMETER}

Place the jacket on a sturdy bench or table in a location that is reasonably free from drafts and is protected from sources of radiant heat, preferably in an air-conditioned room. Temperature changes in the room should be minimal. There should be convenient access to running water, to a drain and to an appropriate grounded electrical outlet. About 8 square feet of workspace will be required. The lab assistant will provide already-weighed test samples. A balance capable of weighing up to $2.0 \mathrm{~kg}$ with $0.1 \mathrm{~g}$ sensitivity, and a tank of oxygen are available in the lab. All operations required to test an unknown sample or to standardize the 1341 plain calorimeter should proceed step-wise in the following manner:

\section{Prepare the sample and charge the oxygen bomb.}

Precautions. Combustion with oxygen in a sealed bomb is a very effective and reliable method for releasing all heat energy obtainable from a sample and for preparing hydrocarbon compounds and carbonaceous materials for analysis, but there are certain precautions, which must always be observed when using this equipment. In particular:

- Do not overcharge the bomb with too much sample or with a sample, which might react with explosive violence.

- Do not overcharge the bomb with too much oxygen. The initial charging pressure should not exceed 40 $\operatorname{atm}(590 \mathrm{psig})$. About $30 \mathrm{~atm}$ is recommended here.

- Do not fire the bomb alone on an open bench without providing a protective cooling medium. Usually the bomb should be completely submerged in water during firing.

- Do not fire the bomb if gas bubbles are released from any point on the bomb when it is submerged in water.

- Do not ignite a volatile sample without using one of the sealed sample holders (which would be provided).

- Stand away from the bomb during firing and do not handle the bomb for at least 1 minute after firing.

- Keep the bomb in good condition at all times. Any parts that show signs of weakness or deterioration must be replaced promptly.

Allowable Sample Size. To stay within safe limits, the bomb should never be charged with a sample, which will release more than 8000 calories when burned in oxygen, and the initial oxygen pressure should never exceed 40 atmospheres (590 psig.). To avoid damage to the bomb and possible injury to the operator, it should be a standing rule in each laboratory that the bomb must never be charged with more than 1 of the samples provided (approx $1 \mathrm{~g}$ ) of material.

Attaching the Fuse. Set the bomb head on the A38A support stand and fasten a $10 \mathrm{~cm}$ length of fuse wire between the two electrodes. Parr $45 \mathrm{C} 10$ nickel alloy wire, used for most tests, is furnished on cards from which uniform $10 \mathrm{~cm}$ lengths can be cut.

To attach the fuse to quick-grip electrodes, insert the ends of the wire into the eyelet at the end of each stem and push the cap downward to pinch the wire into place. No further threading or twisting is required. 
Place the fuel capsule with its weighed sample in the electrode loop and bend the wire downward toward the surface of the charge. It is not necessary to submerge the wire in a powdered sample. In fact, better combustion will usually be obtained if the loop of the fuse is set slightly above the surface. When using pelleted samples, bend the wire so that the loop bears against the top of the pellet firmly enough to keep it from sliding against the side of the capsule. It is also good practice to tilt the capsule slightly to one side so that the flame emerging from it will not impinge directly on the tip of the straight electrode.

Liquids in the Bomb. Most bomb combustion procedures call for a small amount of liquid to be placed in the bottom of the bomb as a sequestering agent and absorbent. If the amount and type of liquid are not otherwise specified, add $1.0 \mathrm{~mL}$ of distilled or deionized water from a pipet

Closing the Bomb. Care must be taken not to disturb the sample when moving the bomb head from the support stand to the bomb cylinder. Check the sealing ring to be sure that it is in good condition and moisten it with a bit of water so that it will slide freely into the cylinder; then slide the head into the cylinder and push it down as far as it will go. For easy insertion, push the head straight down without twisting and leave the gas release valve open during this operation. Set the screw cap on the cylinder and turn it down firmly by hand to a solid stop. When properly closed, no threads on the cylinder should be exposed. If the screw cap tends to bind to the cylinder at this point, indicating that it might be difficult to open the bomb after it has been fired, turn the screw cap back slightly - but only a few degrees - enough to release the binding, since the bottom thread must remain fully engaged. It is not necessary to use a wrench or spanner on the screw cap. Hand tightening should be sufficient to secure a tight seal.

Filling the Bomb. The pressure connection to the bomb is made with a slip connector on the oxygen hose, which slides over the gas inlet fitting on the bomb head. Slide the connector onto the inlet valve body and push it down as far as it will go. If it does not slide easily, a drop of water spread around the inlet valve will lubricate the sealing rings. Close the outlet valve on the bomb head; then open or "crack" the oxygen tank valve not more than one-quarter turn. Open the filling connection control valve slowly and watch the gage as the bomb pressure rises to the desired filling pressure (usually 27 atm., but never more than $40 \mathrm{~atm}$.); then close the control valve. The bomb inlet check valve will close automatically when the oxygen supply is shut off, leaving the bomb filled to the highest pressure indicated on the 0-55 atm. gage. Release the residual pressure in the filling hose by pushing downward on the lever attached to the relief valve. The gage should now return to zero. If the pressure drops slowly and a large amount of gas escapes when the pressure relief valve is opened, the check valve in the bomb head is not operating properly. This trouble will have to be corrected before the bomb can be used. If too much oxygen should accidentally be introduced into the bomb, do not proceed with the combustion. Detach the filling connection; exhaust the bomb; remove the head and reweigh the sample before repeating the filling operation.

2. Fill the calorimeter bucket by first taring the dry bucket on a solution or trip balance; then add $2000(+/-0.5)$ grams of water. The water temperature should be approximately $1.5^{\circ} \mathrm{C}$ below room temperature, but not less than about $19.2^{\circ} \mathrm{C}$.

3. Set the bucket in the calorimeter, noting the three dimples in the bottom of the bucket, which rest on supporting pins in the bottom of the jacket. The single dimple must always face forward when setting the bucket in the jacket.

Attach the lifting handle to the two holes in the side of the screw cap and lower the bomb into the water with its feet spanning the circular boss in the bottom of the bucket. Handle the bomb carefully during this operation so that the sample will not be disturbed. Remove the handle and shake any drops of water back into the bucket; then push the two ignition lead wires into the terminal sockets on the bomb head, being careful not to remove any water from the bucket with the fingers.

4. Connect the ignition unit. The Parr 2901 Ignition Unit operates from any standard electrical outlet to provide the proper low voltage firing current, providing also a convenient push switch, indicating lamp and connecting terminals. Connect the two lead wires from the calorimeter jacket to the "10 CM" terminals on the ignition unit; then plug the power cord into any appropriate grounded electrical outlet. After the unit has been plugged into an 
outlet do not press the firing button unless the lead wires inside the jacket are connected to a bomb. If the bare terminals on these wires happen to be in contact with each other or with a metal object when the circuit is closed, the resulting short-circuit may cause serious damage to the ignition system.

5. Set the cover on the jacket with the thermometer facing toward the front. Turn the stirrer by hand to be sure that it runs freely; then slip the drive belt onto the pulleys and start the motor.

6. Let the stirrer run for 5 minutes to reach equilibrium before starting a measured run. At the end of this period record the time or start a timer and read the temperature.

7. Read and record temperatures at one-minute intervals for 6 minutes. Then, at the start of the 6 th minute...

8. Stand back from the calorimeter and fire the bomb by pressing the ignition button and holding it down until the indicator light goes out. Normally the light will glow for only about $1 / 2$ second but release the button within 5 seconds regardless of the light. Caution: Do not have the head, hands or any parts of the body over the calorimeter when firing the bomb; and continue to stand clear for 30 seconds after firing.

9. The bucket temperature will start to rise within 20 seconds after firing. This rise will be rapid during the first few minutes; then it will become slower as the temperature approaches a stable maximum as shown by the typical temperature rise curve on page 4 .

10. Measure the time required to reach 60 per cent of the total rise. Take temperature readings at $45,60,75$, 90 and 105 seconds after firing and interpolate between these readings to identify the $60 \%$ point after the total rise has been measured.

11. After the rapid rise period (about 4 or 5 minutes after ignition) record temperatures at one-minute intervals until the difference between successive readings has been constant for five minutes. Usually the temperature will reach a maximum; then drop very slowly. But this is not always true since a low starting temperature may result in a slow continuous rise without reaching a maximum. As stated above, the difference between successive readings must be noted and the readings continued at one-minute intervals until the rate of the temperature change becomes constant over a period of 5 minutes.

12. After the last temperature reading, stop the motor, remove the belt and lift the cover from the calorimeter. Wipe the stirrer with a clean cloth and set the cover on the support stand. Lift the bomb out of the bucket; remove the ignition leads and wipe the bomb with a clean towel.

13. Open the knurled knob on the bomb head to release the gas pressure before attempting to remove the cap. This release should proceed slowly over a period of not less than one minute to avoid entrainment losses. After all pressure has been released, unscrew the cap; lift the head out of the cylinder and place it on the support stand. Examine the interior of the bomb for soot or other evidence of incomplete combustion. If such evidence is found, the test will have to be discarded.

14. Wash all interior surfaces of the bomb with water and dry carefully.

15. Remove all unburned pieces of fuse wire from the bomb electrodes; straighten them and measure their combined length in centimeters. Subtract this length from the initial length of 10 centimeters and enter this quantity on the data sheet as the net amount of wire burned, $\mathrm{L}_{\mathrm{f}}$. 
PARTS FOR THE 1341 CALORIMETER

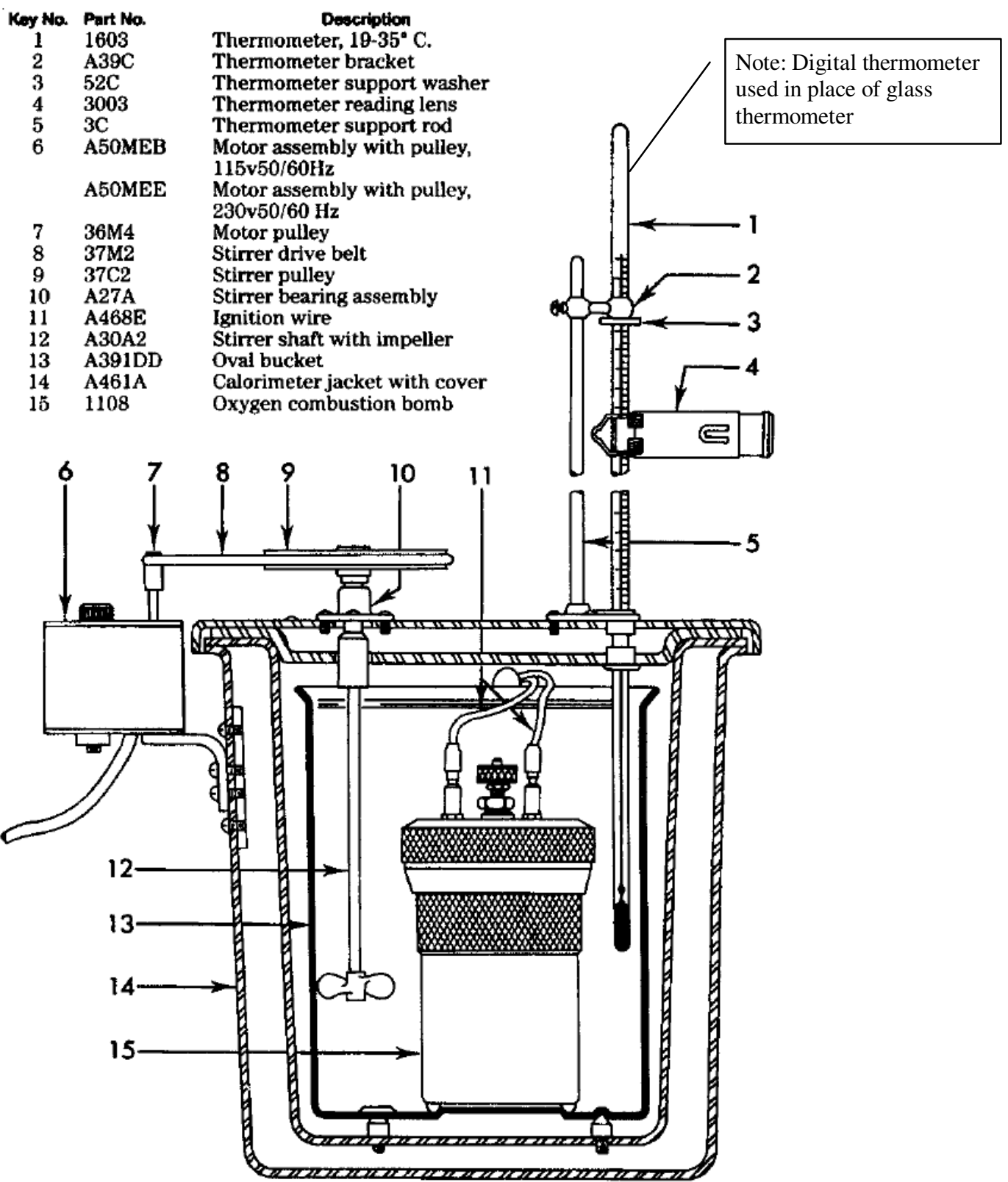

PARR INSTRUMENT COMPANY

211 Fifty-Third Street, Moline, Illinois 61265 USA Phone 309/762-7716 Fax 309/762-9453

Telex 270226 


\section{PRELIMINARY CALCULATIONS}

The raw data should be plotted, as shown below, and inspected for anomalies. There are a few features worth noting. First, the data should have a very slight positive slope during the Pre-period (if the initial water temperature is about $1.5^{\circ} \mathrm{C}$ below room temperature to start). During the Post-period, there should be a very slight negative slope. Calculations are based on identifying the Pre and Post-periods, and on identifying the time to achieve 60\% of the total temperature rise.

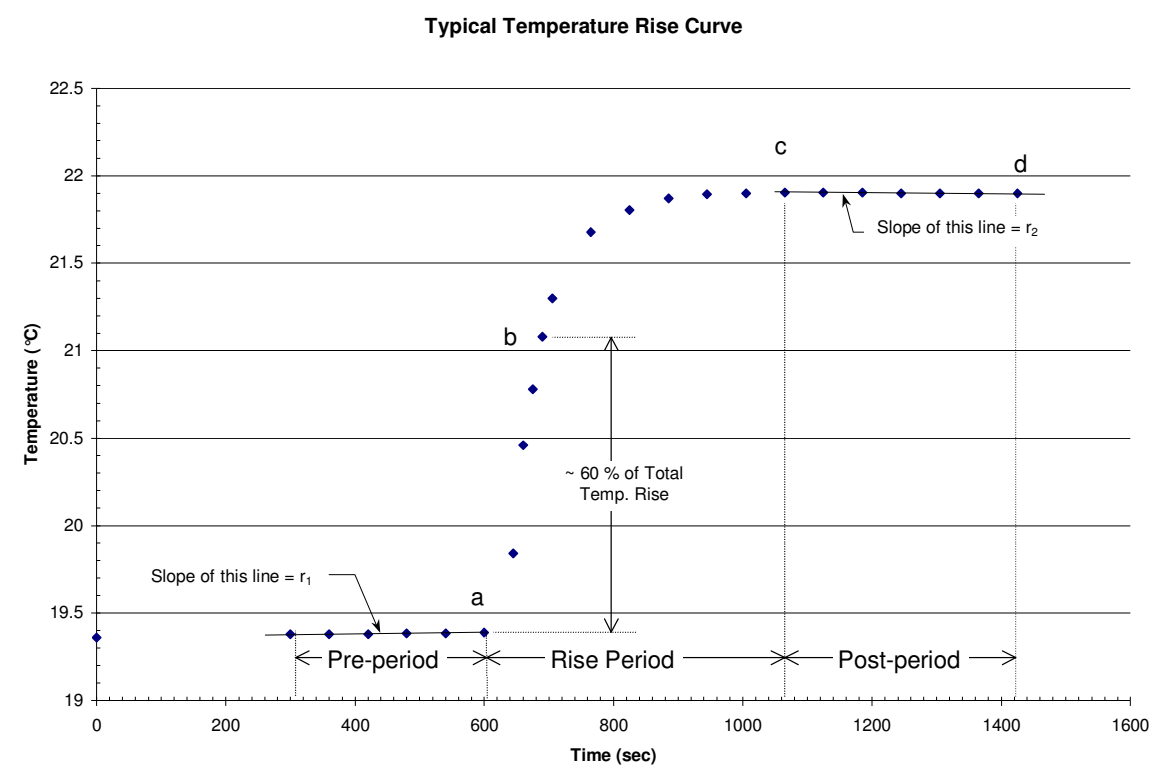

Assembly of Data. The following data should be available at the completion of a test in a 1341 calorimeter:

$\mathrm{a}=$ time of firing

$\mathrm{b}=$ time when the temperature reaches 60 percent of the total rise

$\mathrm{c}=$ time at beginning of period in which the rate of temperature change has become constant

$\mathrm{T}_{\mathrm{a}}=$ temperature at time of firing

$\mathrm{T}_{\mathrm{c}}=$ temperature at time $\mathrm{c}$

$\mathrm{r}_{1}=$ rate (temperature units per time, ${ }^{\circ} \mathrm{C} / \mathrm{sec}$ ) at which temperature was rising during the 5-min. period before firing

$\mathrm{r}_{2}=$ rate (temperature units per time, ${ }^{\circ} \mathrm{C} / \mathrm{sec}$ ) at which the temperature was rising during the 5 -min. period after time $c$. If the temperature was falling instead of rising after time $c, r_{2}$ is negative and the quantity $-r_{2}(c-b)$

becomes positive and must be added when computing the corrected temperature rise

$\mathrm{L}_{\mathrm{f}}=$ centimeters of fuse wire consumed in firing

$C_{t h_{\text {Cal }}}=$ thermal capacitance of the calorimeter, determined under CALIBRATING THE COMBUSTION

BOMB

$\mathrm{M}_{\mathrm{S}}=$ mass of test sample in grams

$\mathrm{M}_{\mathrm{gc}}=$ mass of gelatin capsule used to contain fuel sample (if used)

Temperature Rise. Compute the net corrected temperature rise, $\Delta \mathrm{T}$, by substituting in the following equation:

$\Delta \mathrm{T}=\left(\mathrm{T}_{\mathrm{c}}-\mathrm{T}_{\mathrm{a}}\right)-\mathrm{r}_{1}(\mathrm{~b}-\mathrm{a})-\mathrm{r}_{2}(\mathrm{c}-\mathrm{b})$

Thermochemical Corrections: Compute the following for each test:

$\mathrm{E}_{\text {equiv/f }}=\left(\mathrm{L}_{\mathrm{f}}\right)\left(\mathrm{e}_{\text {equiv/f }}\right)=$ correction in calories for heat of combustion of fuse wire $=\left(\mathrm{L}_{\mathrm{f}}\right.$ in $\left.\mathrm{cm}\right) \times(2.3 \mathrm{cal} / \mathrm{cm}) \quad$ (when using Parr $45 \mathrm{C} 10$ nickel chromium fuse wire)

$\mathrm{E}_{\text {equiv/gc }}=\mathrm{M}_{\mathrm{gc}}\left(\mathrm{e}_{\text {equiv/gc }}\right)=$ correction in calories for the heat of combustion of the gelatin capsule (if used) $=\left(\mathrm{M}_{\mathrm{gc}}\right.$ in grams $) \times(4600$ calories/gm $)$ 


\section{Calibrating the Combustion Bomb Calorimeter}

The constant volume combustion bomb (bomb) has been calibrated using a standard sample of benzoic acid according to the procedure below. Some simplifications have been made, but the resulting accuracy is certainly adequate for the purposes of this laboratory experiment.

The calibration is based on a simple First Law analysis of the bomb. Once the bomb has been calibrated, a similar analysis may be used to obtain the energy value of any test sample. Please refer to the sketch below.

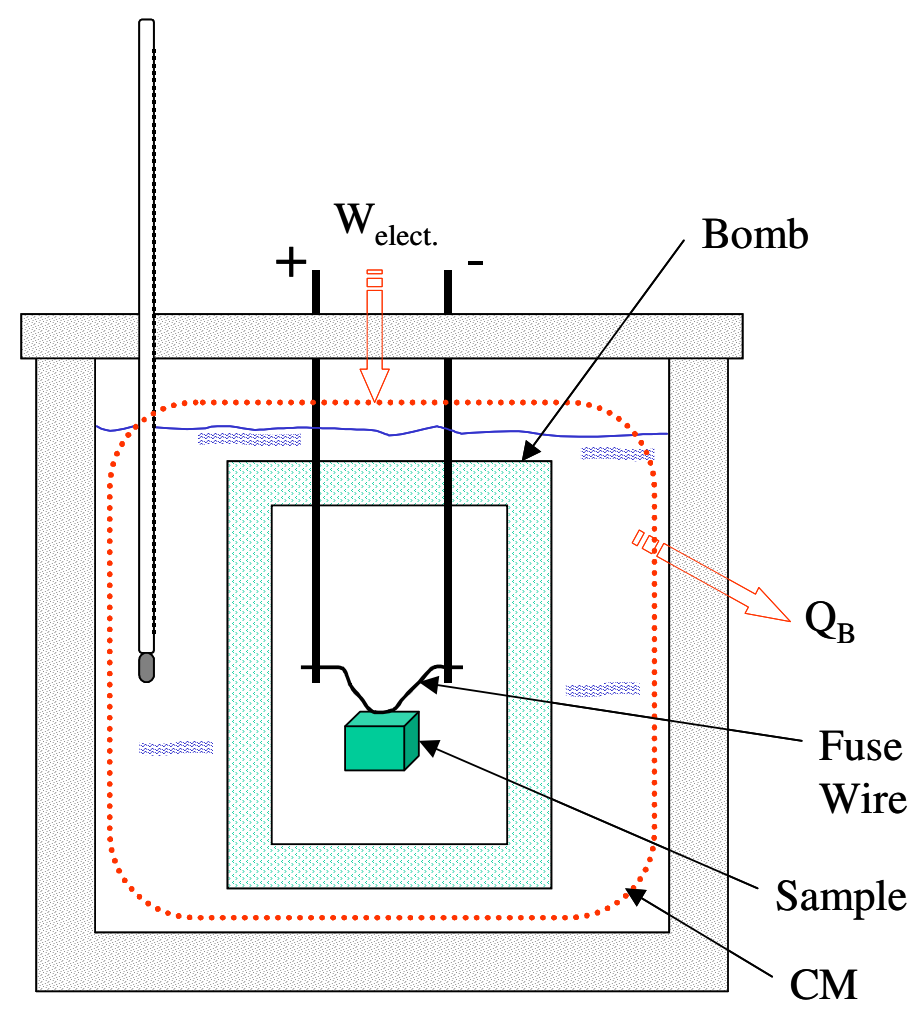

For the process of igniting the fuse and the test sample, and the resulting rise in water temperature, the $1^{\text {st }}$ Law states that:

so that,

$$
\mathrm{E}_{2}-\mathrm{E}_{1}=\text { Energy In }- \text { Energy out }
$$

$$
\Delta \mathrm{E}=\mathrm{W}_{\text {elect. }}-\mathrm{Q}_{\mathrm{B}}
$$

Since Energy is extensive, and changes in kinetic and potential energy are negligible,

where subscripts,

$$
\Delta \mathrm{E}=\Delta \mathrm{U}=\Delta \mathrm{U}_{\mathrm{s}}+\Delta \mathrm{U}_{\mathrm{f}}+\Delta \mathrm{U}_{\mathrm{w}}+\Delta \mathrm{U}_{\mathrm{B}}
$$

$$
\begin{aligned}
& \mathrm{S}=\text { test sample } \\
& \mathrm{f}=\text { fuse wire } \\
& \mathrm{W}=\text { water surrounding bomb } \\
& \mathrm{B}=\text { bomb }
\end{aligned}
$$




$$
\begin{gathered}
\Delta=(\text { final state }- \text { initial state }) \\
1=\text { initial state } \\
2=\text { final state }
\end{gathered}
$$

Substituting for $\Delta \mathrm{E}$, the $1^{\text {st }}$ Law becomes,

$$
\Delta \mathrm{U}_{\mathrm{s}}+\Delta \mathrm{U}_{\mathrm{f}}+\Delta \mathrm{U}_{\mathrm{w}}+\Delta \mathrm{U}_{\mathrm{B}}=\mathrm{W}_{\text {elect. }}-\mathrm{Q}_{\mathrm{B}}
$$

Combining terms associated with combustion, and separately those associated with resulting temperature rise,

$$
\Delta \mathrm{U}_{\mathrm{w}}+\Delta \mathrm{U}_{\mathrm{B}}+\mathrm{Q}_{\mathrm{B}}=-\Delta \mathrm{U}_{\mathrm{s}}-\Delta \mathrm{U}_{\mathrm{f}}+\mathrm{W}_{\text {elect. }}
$$

Reviewing the equation, term by term:

$>\Delta \mathrm{U}_{\mathrm{w}}=$ energy rise in the water bath $=\mathrm{M}_{\mathrm{w}} \mathrm{c}_{\mathrm{v}_{\mathrm{w}}}\left(\mathrm{T}_{2}-\mathrm{T}_{1}\right)$

$>\Delta \mathrm{U}_{\mathrm{B}}=$ energy rise in the combustion bomb $=\mathrm{M}_{\mathrm{B}} \mathrm{c}_{\mathrm{v}_{\mathrm{B}}}\left(\mathrm{T}_{2}-\mathrm{T}_{1}\right)$

$>\mathrm{Q}_{\mathrm{B}}=$ heat transfer out of the bomb. $\mathrm{Q}_{\mathrm{B}}$ is approximately proportional to the temperature rise, and so the quantity $\left(\frac{Q_{B}}{\left(T_{2}-T_{1}\right)}\right)$ is approximately constant.

$>-\Delta \mathrm{U}_{\mathrm{s}}=-\left(\mathrm{U}_{\text {products }}-\mathrm{U}_{\text {reactan ts }}\right)_{\mathrm{s}}=\left(\mathrm{U}_{\text {react. }}-\mathrm{U}_{\text {prod. }}\right)_{\mathrm{s}}=$ total "energy release" from the test sample $=\mathrm{M}_{\mathrm{s}} \mathrm{e}_{\mathrm{s}}$; where $\mathrm{e}_{\mathrm{s}}=$ "energy value" per unit mass of the test sample

$>-\Delta \mathrm{U}_{\mathrm{f}}=\left(\mathrm{U}_{\text {react. }}-\mathrm{U}_{\text {prod. }}\right)_{\mathrm{f}}=\mathrm{L}_{\mathrm{f}}\left[\frac{\left(\mathrm{U}_{\text {react. }}-\mathrm{U}_{\text {prod. }}\right)_{\mathrm{f}}}{\mathrm{L}_{\mathrm{f}}}\right]=\mathrm{L}_{\mathrm{f}} \mathrm{e}_{\mathrm{f}} \quad$ where, $\mathrm{e}_{\mathrm{f}}$ is the "energy value" per unit length of the fuse material, and $\mathrm{L}_{\mathrm{f}}$ is the actual length of the fuse consumed. ( $\mathrm{L}_{\mathrm{f}}=\mathrm{L}_{\mathrm{f}_{\text {initial }}}-\mathrm{L}_{\mathrm{f}_{\text {final }}}$ )

$>\mathrm{W}_{\text {elect. }}=$ electrical work necessary to ignite the fuse, and is proportional to the length of fuse consumed $=\mathrm{L}_{\mathrm{f}} \mathrm{w}_{\mathrm{f}}$

Substituting the above back into the energy equation,

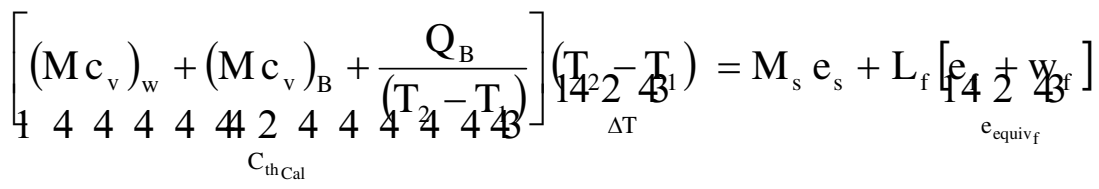


The first term on the left, in brackets, is composed of terms that are approximately constant and together represent the thermal "inertia" or "thermal capacitance" of the calorimeter. The term in brackets on the right represents the "energy equivalent per length of fuse material" ( $e_{\text {equiv }_{f}} \cong 2.3$ $\mathrm{Cal} / \mathrm{cm})$. The $1^{\text {st }}$ Law can then be written as,

$$
\mathrm{C}_{\mathrm{th}_{\mathrm{Cal}}} \Delta \mathrm{T}=\mathrm{M}_{\mathrm{s}} \mathrm{e}_{\mathrm{s}}+\mathrm{L}_{\mathrm{f}} \mathrm{e}_{\text {equiv }_{\mathrm{f}}}
$$

Solving for the thermal capacitance of the calorimeter,

$$
\mathrm{C}_{\text {th }_{\text {Cal }}}=\frac{\mathrm{M}_{\mathrm{s}} \mathrm{e}_{\mathrm{s}}+\mathrm{L}_{\mathrm{f}} \mathrm{e}_{\text {equiv }_{\mathrm{f}}}}{\Delta \mathrm{T}}
$$

Following replicate calibration tests with a reference benzoic acid test sample, it was found that,

$$
\mathrm{C}_{\mathrm{th}_{\mathrm{Cal}}}=2437 \pm 20 \text { calories } /{ }^{\circ} \mathrm{C} \text {, or } . \mathrm{C}_{\mathrm{th}_{\mathrm{Cal}}}=2467 \pm 20 \text { calories } /{ }^{\circ} \mathrm{C} \text { (unit \#2). }
$$

This value can now be used in conjunction with the temperature rise to account for the energy increase in the water bath and combustion bomb, as well as the heat transfer from the calorimeter when analyzing other test samples. 


\section{Lab Experiment \#2: Energy Content of Food}

Group \# =

Date $\&$ Time $=$

Sample \# =

Sample Wt. =

Starting $\mathrm{H}_{2} \mathrm{O}$ Temp. =

\begin{tabular}{|c|c|c|}
\hline Time (seconds) & Temperature $\left({ }^{\circ} \mathrm{C}\right)$ & Comment \\
\hline $\begin{array}{l}0 \\
\end{array}$ & & start timer \\
\hline 60 & & \\
\hline 120 & & \\
\hline 180 & & \\
\hline 240 & & \\
\hline 300 & & $<-$-start logging temperature \\
\hline 360 & & pre-period \\
\hline 420 & & " " " \\
\hline 480 & & $"$ \\
\hline 540 & & " \\
\hline 600 (ignite time) & & begin rise period \\
\hline 645 & & \\
\hline 660 & & \\
\hline 675 & & \\
\hline 690 & & \\
\hline 705 & & \\
\hline 765 & & \\
\hline 825 & & \\
\hline 885 & & \\
\hline 945 & & \\
\hline 1005 & & \\
\hline 1065 & & \\
\hline 1125 & & \\
\hline 1185 & & \\
\hline 1245 & & \\
\hline 1305 & & \\
\hline 1365 & & \\
\hline 1425 & & \\
\hline 1485 & & \\
\hline 1545 & & \\
\hline
\end{tabular}

Group Leader: 